\title{
ANKYLOSIS OF THE FINGER JOINTS IN RHEUMATOID ARTHRITIS
}

\author{
BY \\ ROBERT M. STECHER \\ From the Department of Medicine of Western Reserve Medical School, City Hospital, Cleveland, Ohio
}

The ordinary manifestations of rheumatoid arthritis are well known and readily recognized. They are subject to wide variations and, as they deviate farther from the conventional picture, diagnosis becomes difficult, doubtful, or even impossible. The aetiology is unknown and proof of diagnosis is lacking. Even the proposed diagnostic criteria for rheumatoid arthritis (Ropes, Bennett, Cobb, Jacox, and Jessar, 1957) have not completely eliminated the difficulty, although they have made greater uniformity of classification possible. Under such circumstances, doubtful cases conforming to some diagnostic criteria but not to others are of considerable interest and often worthy of detailed study. Bony ankylosis of joints is a characteristic result of rheumatoid arthritis in a small proportion of cases, but it is non-specific for the disease. Several cases in which ankylosis of the finger joints has occurred or has been an outstanding feature have been observed which seem worthy of further attention and will be described here. In two such cases, ankylosis of the interphalangeal joints of the fingers were observed in long-standing, generalized, and severely crippling rheumatoid arthritis. These cases are described briefly for comparison. Two other cases, however, have been followed for several years, one through a period of soft tissue inflammation and bone destruction, progressing into ankylosis. The trouble with the fingers has been the outstanding complaint. No other joints have been involved, general health has not been impaired, and since the inflammation has subsided, immobility of the fingers has been the only complaint.

\section{Case Reports}

Case 1, a woman aged 52, entered the City Hospital in 1933. Her hospital record has been lost so that the clinical story is not available in detail. She had then had generalized rheumatoid arthritis for some years and was bedridden and completely handicapped. According to diagnostic criteria she was classified as a case of definite rheumatoid arthritis. According to the therapeutic criteria adopted by the New York Rheumatism Association and the American Rheumatism Association (Steinbrocker, Traeger, and Batterman, 1949), she was classified as "Stage IV Class IV", because of osteoporosis, cartilage and bone destruction, muscle atrophy, ulnar deviation, and bony ankylosis.

The hands show little deformity (Fig. 1). The wrists

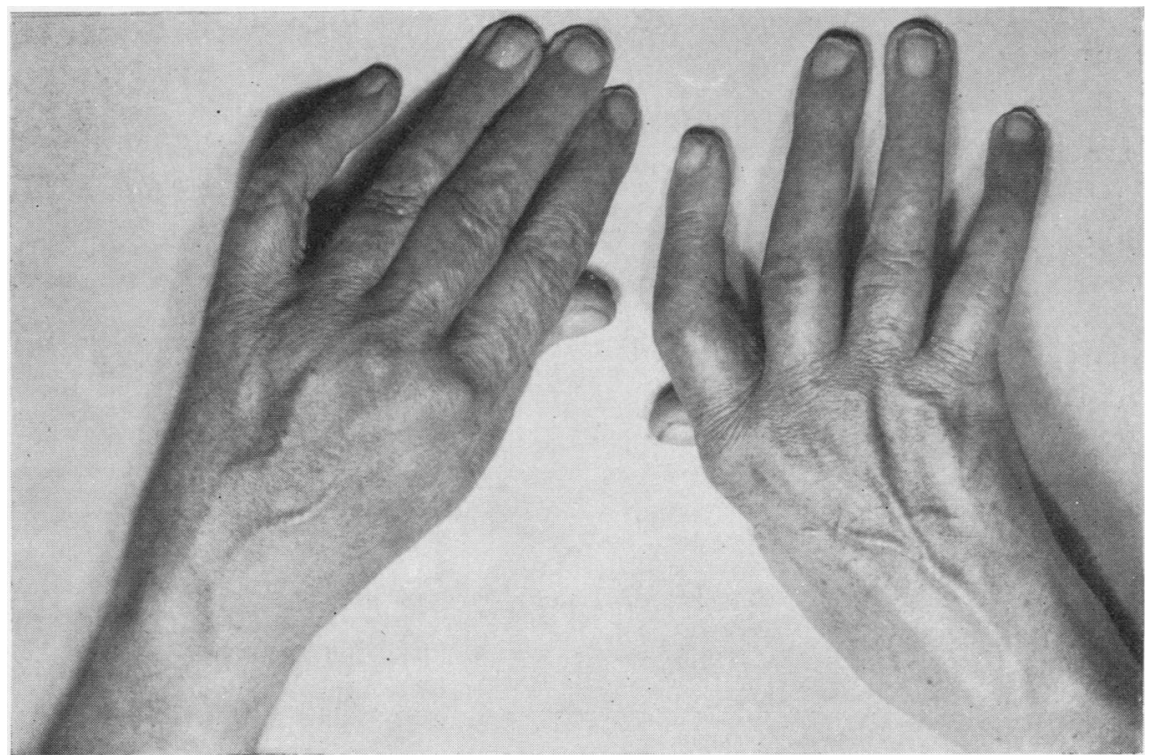

Fig. 1.-Case 1, hands, showing slight swelling of wrists, ulnar deviation of fingers of right hand, and flexion of right forefinger and left little finger. Loss of transverse creases of the skin of the backs of the fingers is noticeable. The finger nails are normal. 
seem to be slightly swollen, and there is obvious ulnar deviation of the fingers of the right hand, the fingers are straight except for slight flexion of the right forefinger and the left little finger, and the skin of the fingers of the right hand is particularly smooth with loss of the normal transverse creases over the proximal joints. These creases have completely disappeared over the distal joints and the fingers here seen to be constricted. The nails are normal.

Radiographs of the hands (Fig. 2) show marked demineralization of the bones, particularly around the wrists and metacarpophalangeal and interphalangeal joints of both hands. The metacarpal bones of the wrists have lost their individual outlines and have been fused into one bony mass. The joint spaces between them and the carpal bones have completely disappeared and are diminished between them and the bones of the lower arm. All the metacarpophalangeal joints show subluxation with destruction of the proximal phalanges. The fingers of the right hand show ulnar deviation. All the interphalangeal joints, save only the distal joint of the left little finger, show complete bony ankylosis.

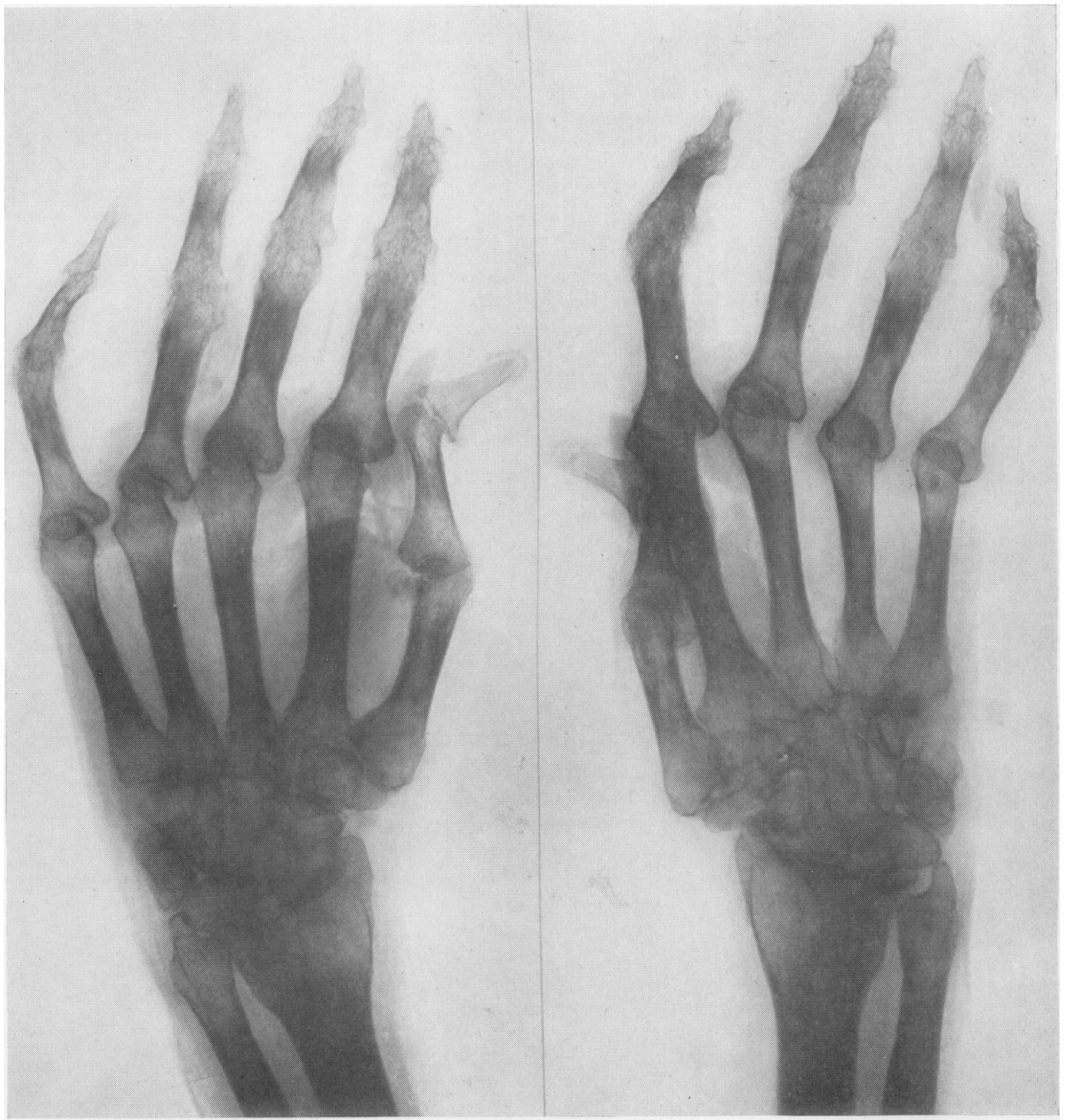

Fig. 2.-Case 1, postero-anterior radiographs, showing bony ankylosis of all finger joints and subluxation of the metacarpophalangeal joints. The bones of the wrist are fused and ankylosed to the radius and ulna and metacarpal bones in both hands. There is also generalized demineralization. 


\section{ANKYLOSIS OF THE FINGER JOINTS IN RHEUMATOID ARTHRITIS}

There was also demineralization and severe loss of joint space of the right knee and condensation of bone and loss of joint spaces in both hips.

This woman had had severe generalized rheumatoid arthritis for many years resulting in complete disability and invalidism. One outstanding feature of the disease in her case was ankylosis of all finger joints.

Case 2, a woman aged 42, was an in-patient from April to December, 1936, because of severe generalized rheumatoid arthritis of long duration. The disease had begun 8 years before with arthritis of the feet, and this had spread to involve the hands, shoulders, knees, and elbows. The pain at times was severe and stiffness developed. She became so disabled that she could not walk and had been confined to a wheel chair for the last 7 years. On admission there was marked limitation of motion of nearly all of her joints and complete stiffness of all of the proximal joints. She was classified as a case of definite rheumatoid arthritis (Stage IV, Class IV). Attempts to correct her flexion deformities were unsuccessful and she was discharged.

The hands showed some enlargement of the wrists. There was little abnormality in the hands except that the skin over the fingers was smooth, all of the normal transverse creases over all the finger joints having been lost. The finger nails were normal.

Radiographs of both hands (Fig. 3) 8 years after the onset show demineralization of bones particularly marked in the phalanges. There is bone absorption of the carpal bones, worse in the right wrist, with fusion to each other, the metacarpal bones, and the lower arm bones. Subluxation is seen in most of the metacarpophalangeal joints. All the interphalangeal joints, except the joints of the right index and middle fingers, are the seat of bony ankylosis.

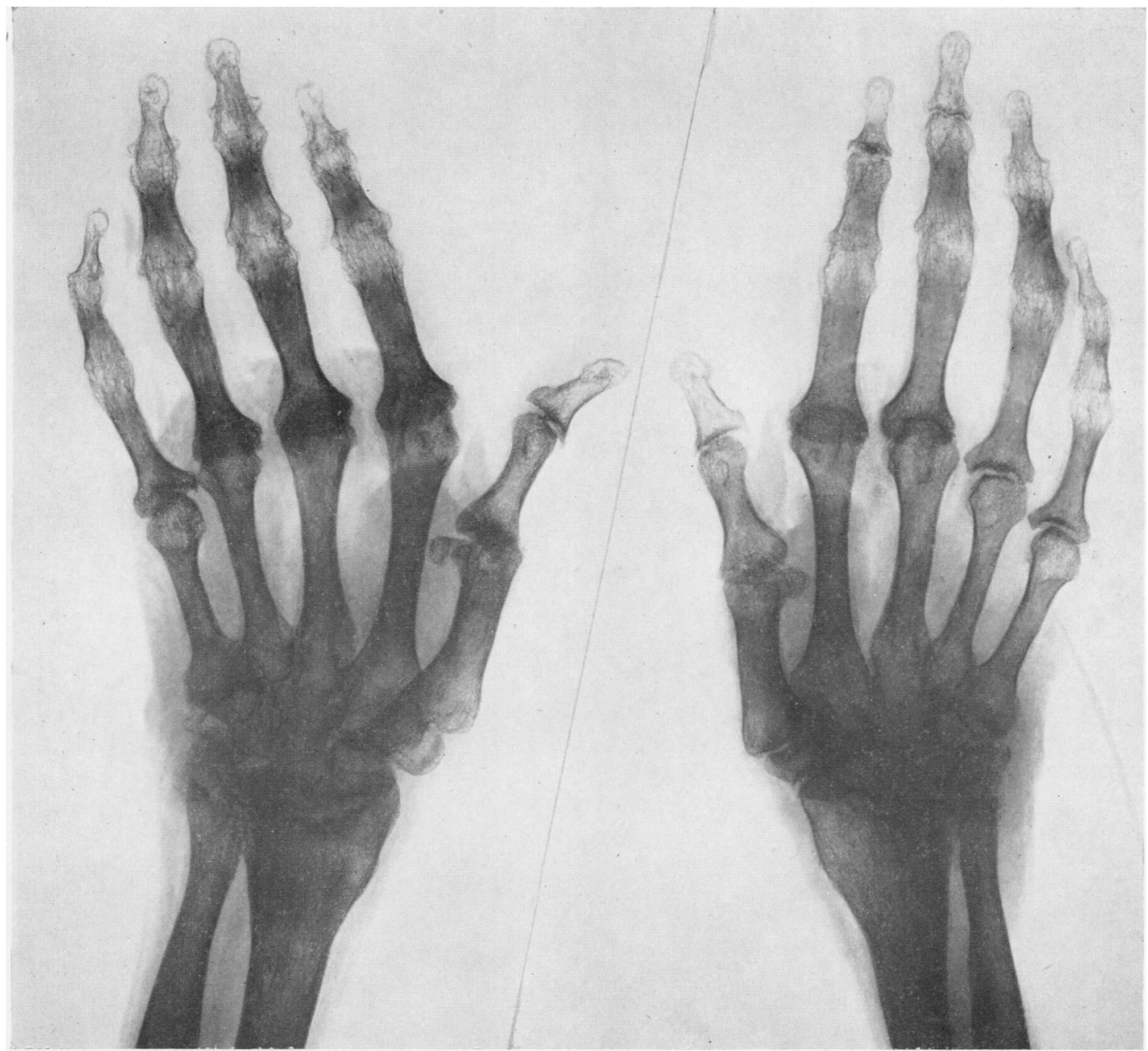

Fig. 3.-Case 2, postero-anterior radiographs of both hands 8 years after onset, showing demineralization of bones which is particularly marked in the phalanges. Absorption of the carpal bones is seen, which is more marked in the right wrist with fusion to each other, to the metacarpal bones, and to the radius and ulna. Most of the interphalangeal joints show bony ankylosis. 
This woman had had severe generalized rheumatoid arthritis for 8 years, resulting in complete disability and invalidism. One outstanding feature of the disease in her case was ankylosis of nearly all finger joints.

Case 3, a woman aged 50, was first seen in March, 1947. Her disease had started 11 years before, at the age of 39, with swelling and pain in her hands. Limitation of motion in the fingers had been noted shortly afterwards and this had progressed so that in 1945 they had become stiffened, but after this the pain and swelling had disappeared. Pains in the feet had begun in 1940, 7 years before her first visit to hospital. They had persisted and increased in severity and had been associated at times with tenderness and swelling. For several years she had had pain in the right wrist, shoulders, hips, and knees. Her general health was fairly good but she slept poorly. Despite a poor appetite she had gained $15 \mathrm{lb}$. in 3 years. She kept her house warm, felt worse in rainy and damp weather, and had frequent chilly and nervous spells. She had been treated with innumerable hip shots, short-wave diathermy treatments, high colonic irrigations, and aspirin, and repeatedly told that she had

arthritis. Menses became irregular in 1945, at the age of 47.

Physical examination was negative except for the fingers. They were slightly flexed in the right hand and the joints were obviously ankylosed in the proximal joints. In the left hand motion was present but restricted. All the other joints seemed normal.

She was next seen in January, 1948, with dermatitis medicamentosis, which cleared up after 4 months of treatment. At this time the erythrocyte sedimentation rate was $28 \mathrm{~mm} . \mathrm{Hg} / \mathrm{hr}$. She was next seen at her own home in June, 1952, when she said that the pain had gradually become worse so that she had finally become bedridden. She went on a complete fast for 21 days, then ate salads and fruits for several weeks and again fasted for 27 days. She lost $40 \mathrm{lb}$. in weight during this time, and the joint swelling and pain disappeared and she felt much better. The condition of her fingers was the same, however, except that the entire left little finger had become completely stiffened.

She was free of all complaints and her physical examination was negative except for her joints when she was seen in 1957 and 1958. In 1958 when she clenched her

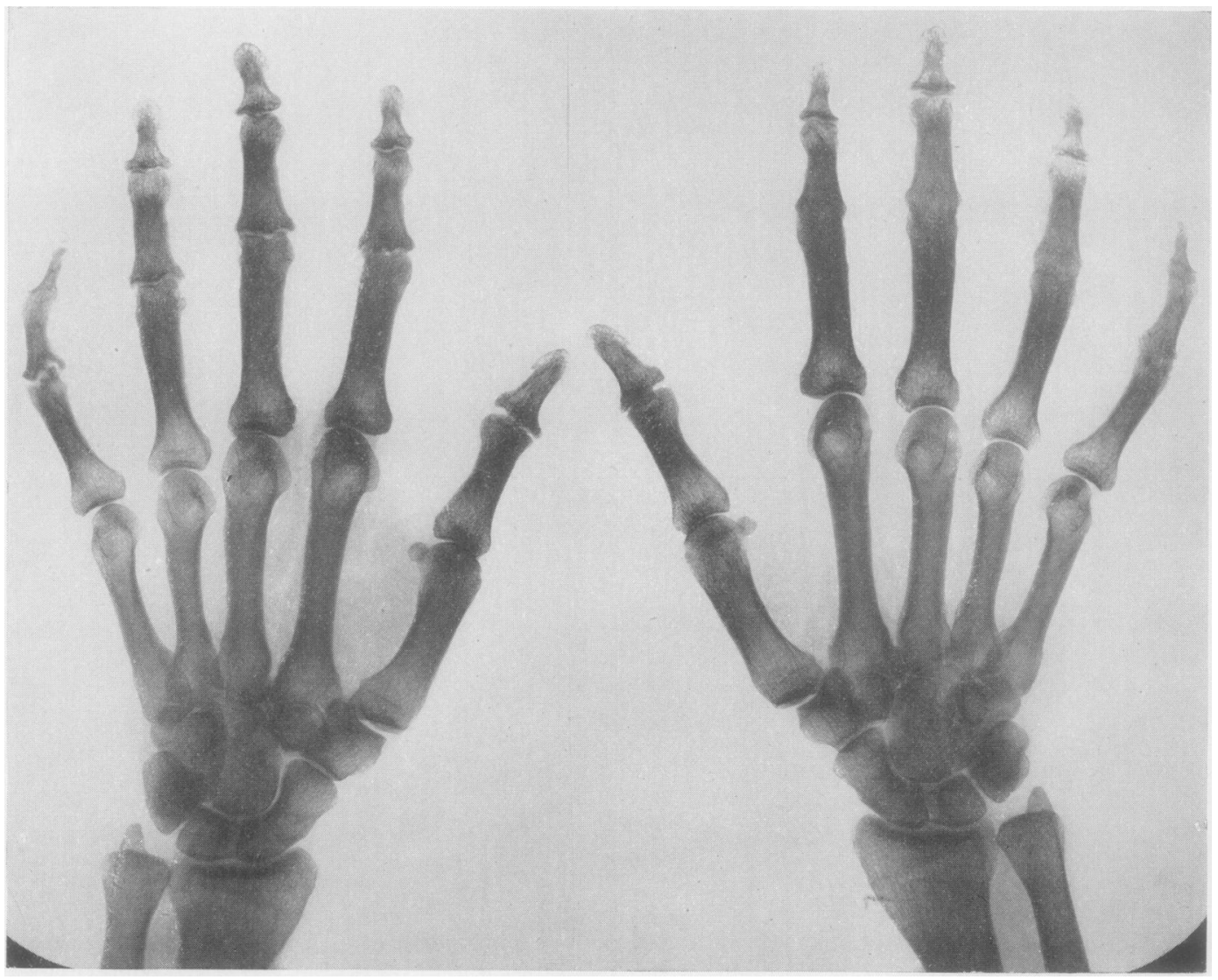

Fig. 4.-Case 3, radiographs of both hands in 1947, 11 years after onset, showing complete ankylosis of all proximal and fifth finger distal joints of the right hand. In the left hand the distal joint of the little finger is ankylosed, the proximal joints show bone destruction and alteration of joint surfaces, which is most marked in the fifth finger. Other bones and joints are normal. 
fists, the metacarpophalangeal joints flexed at rightangles, but the proximal interphalangeal joints remained extended in the right hand and showed very little flexion in the left. Radiographs of the right shoulder, elbow, knee, ankle, and feet, and of the pelvis including the hips were normal.

Clinical laboratory investigations were made in 1947 , 1948, 1953, 1957, and 1958. The red blood count was $3,360,000$ cells per cu. $\mathrm{mm}$. in 1957 , but was otherwise normal, as was the haemoglobin content, white blood cell count, and serum uric acid. The erythrocyte sedimentation rate varied from 28 to $47 \mathrm{~mm}$. $\mathrm{Hg} / \mathrm{hr}$ by a modified Westergren method. Serological tests in September, 1957, showed latex-fixation test positive in 1/320 dilution, Heller F II test positive 1/7,000 dilution, and Waaler-Rose fixation test positive $1 / 1,024$ dilution. Similar results were obtained in January, 1958.

This patient was considered to have rheumatoid arthritis Class IV, Stage I.

Fig. 4 shows an antero-posterior radiograph of both hands taken in 1947. Both wrists and all the metacarpo- phalangeal joints are normal. In the right hand, the proximal interphalangeal joints of the fingers and the distal joint of the little finger are ankylosed. The distal joints of the other three fingers and the thumb are normal. In the left hand the distal joint of the little finger is ankylosed, and the proximal joint is abnormal in that the joint surfaces are irregular and saw-toothed because of irregular bone destruction. The other joints have a slightly similar but not nearly so advanced appearance. Radiographs in 1953 and 1957 showed no change except that ankylosis with stout bony fusion had occurred by 1953 in the proximal joint of the left little finger.

Fig. 5 shows lateral radiographs of each finger taken in 1953. Complete fusion is seen of all joints in both little fingers and of the proximal joints of the fingers of the right hand. All signs of joint lines or joint spaces have been obliterated. The proximal joints of the three fingers of the left hand showed a marked antero-posterior enlargement of the proximal ends of the middle phalanges, giving a cup-shaped appearance of the joint surface with rounded spurs. The distal joints of the first three

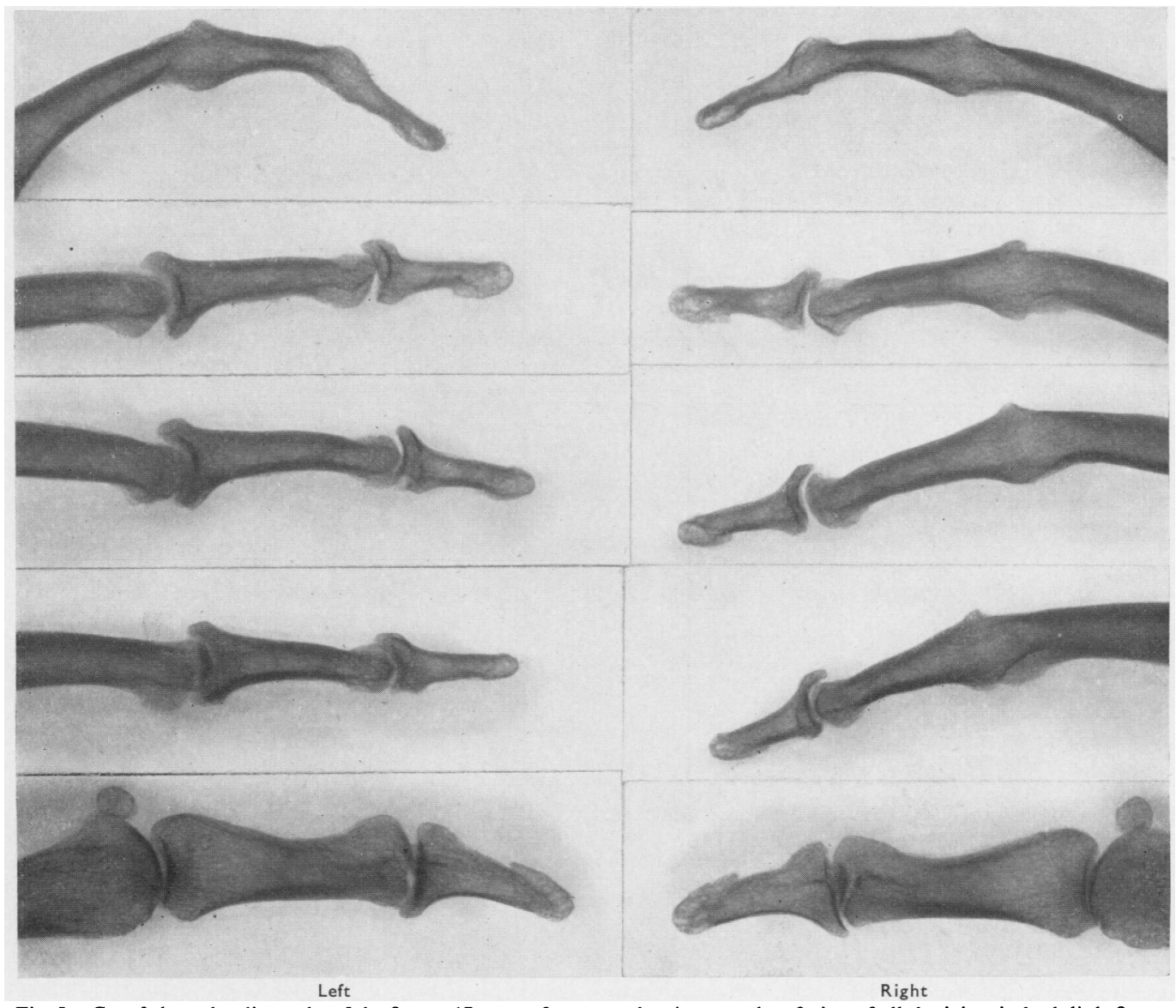

Fig. 5.-Case 3, lateral radiographs of the fingers 17 years after onset showing complete fusion of all the joints in both little fingers and in the proximal joints of the other three fingers of the right hand. The proximal joints of the first three fingers of the left hand show marked antero-posterior enlargement of the proximal ends of the middle phalanges. Spurs are seen on the posterior surface of the distal joints of the first three fingers of each hand similar to those seen in Heberden's nodes. 
fingers all show marked antero-posterior enlargements arising from the dorsal aspect of the proximal end of each of the distal phalanges which resemble those seen in Heberden's nodes (Stecher and Hauser, 1948, 1954). Both thumbs are normal.

Radiographs taken in September, 1957, showed no alteration. Radiographs of both feet, right ankle, right knee, both hips and pelvis, right shoulder, right elbow, both wrists, and all metacarpophalangeal joints showed no sign of arthritic disease or other abnormality. Radiographs of the chest show normal heart and lungs.

Although the distribution of the joint disease is unusual and the lack of constitutional symptoms is surprising, this patient is considered to be a case of rheumatoid arthritis, because of the ankylosis, the consistently elevated sedimentation rate, and the positive agglutination tests. Her disease is now in complete clinical remission.

Case 4, a woman aged 56, was seen in 1949 because of arthritis. She had been completely well until 3 years before when she had noted swelling and soreness of the first two fingers of the right hand. Radiographs taken 2 years later had shown fusiform soft tissue swelling of the right index and middle fingers, loss of joint space, and irregularity with destruction of the bone ends. Slight changes were apparent in the ring finger. All the other joints in the fingers and wrists of both hands were normal. The process had progressed slowly involving other fingers, until all the proximal interphalangeal joints had become enlarged, tender, and partially stiffened. The patient had at different times complained of sore hands, neck, elbows, shoulders, and a toe, but no enlargement, deformity, or dysfunction had developed. Her general health was good. She had lost no weight. She had had much conventional therapy, besides lamp treatments, bee-sting therapy, and hot baths at Hot Springs, Arkansas, and had spent 3 months in Florida without relief. Her family history was negative, in that her parents, five brothers, and sisters had had no joint disease of any kind.

Physical examination was negative except for the fingers, which showed fusiform enlargement of all of the interphalangeal joints including the thumbs. The skin was smooth and shiny, most of the normal wrinkling being decreased or absent over the backs of the distal joints and the proximal joints of the left little and ring fingers and the right index and little fingers and both thumbs. The appearance of the other joints and the skin over the metacarpophalangeal joints and the wrists was completely normal.

The diagnosis at this time was doubtful. Despite the typical appearance of rheumatoid arthritis of the fingers, the diagnosis of osteo-arthritis of the fingers was made because of absence of other joint disease 3 years after onset and because of her normal health and normal laboratory findings.

The patient was next seen in December, 1951, when she was still complaining of stiff and painful wrists, hands, and fingers. Since her previous visit, she had had diathermy treatments and paraffin baths for one year without relief. This was followed by cortisone for 20 days, which gave her relief from pain in the wrists and neck, improved her appetite and digestion, and gave her a feeling of well-being, but oedema developed Acetysalicylic acid and codeine had upset her stomach and had to be discontinued. Gold therapy was sugeo gested but not used. At this visit she was emotionally? disturbed, easily upset, wept readily, and complained of frequent headaches. These symptoms were attributed

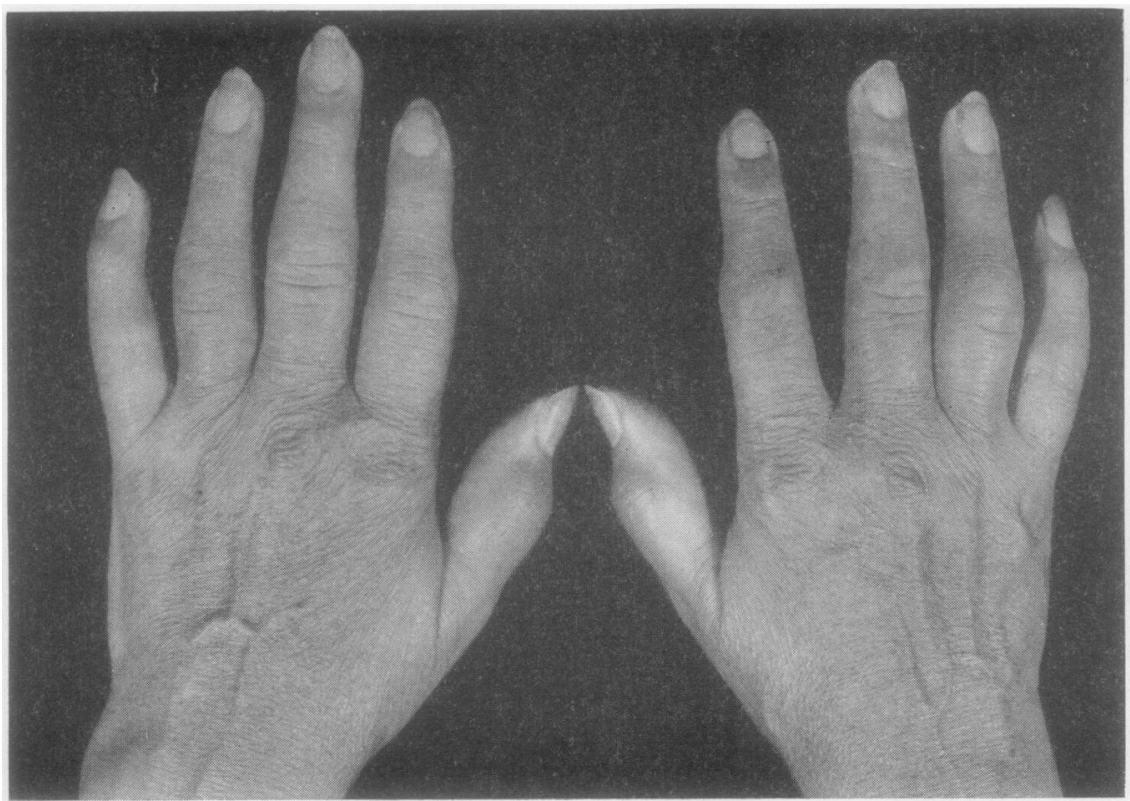

Fig. 6.-Case 4, 3 years after onset; the hands appear normal except for fusiform enlargement of the proximal joints of the fingers and loss of transverse creases of the skin over the terminal joints of the little fingers and thumbs. 
largely to the illness and disability of her husband. Physical examination at this time was negative except for complete ankylosis of all proximal interphalangeal joints.

Little change in her condition was noted on visits in 1952, 1955, and 1957. Cortisone had been started again but this was stopped in 1953 because she had developed a moon face and buffalo hump. She then had 36 gold shots without effect, and since 1953 she has had little or no therapy. Her spirits, her appetite, and her general outlook on life have improved, and despite her bedridden husband whom she cares for at home, she seems happy, contented, and well, with no complaints except a stiffness of the fingers which does not bother her.

Physical examination in 1955 and again in 1958 revealed no abnormality whatsoever in the spine, shoulders, elbows, hips, knees, ankles, or feet. Motion of both wrists were limited to about half the normal range; the interphalangeal joints were fixed, of course, but the other joints of the hand functioned normally.

Laboratory investigations carried out in 1949, 1951, 1952, 1955, 1957, and 1958, showed normal red blood cell count, white blood cell count, haemoglobin level, and haematocrit. The red blood cell sedimentation rate was 21,22 , and $26 \mathrm{~mm}$. $\mathrm{Hg} / \mathrm{hr}$ (corrected) until 1952. In 1955 and 1958 the rate was 9 and $3 \mathrm{~mm}$. respectively.
The latex-fixation test, Heller F II test, and WaalerRose test were negative on May 21, 1957, and January 20, 1958.

If the diagnosis of rheumatoid arthritis is accepted in this case, it can be considered as Class IV, Stage I. The diagnosis is very doubtful, however, because the erythrocyte sedimentation rate has been normal or only slightly elevated, the serological agglutination tests have been negative, and no joint changes have been recognized except those of the hands and the wrists. Except for the ankylosis the joints have not been typical of rheumatoid arthritis. The patient's subjective symptoms can be accounted for by her personal problems.

The progress of the disease in this case can best be followed by examination of photographs and radiographs. Photographs of the hands taken on the first visit in 1949, 3 years after onset (Fig. 6), show fusiform enlargements of the fingers as described above. Radiographs of both hands (first taken in 1948, 2 years after onset) showed, besides demineralization, soft tissue swelling about the proximal interphalangeal joints, decrease in joint space, and destruction of the joint surfaces of the index and middle fingers of the right hand. Radiographs of both hands repeated in May, 1949, (Fig. 7) show extension of the process. The proximal ends of the middle interphalangeal joints are broadened, roughened, and eroded, indicating loss of bone substance.

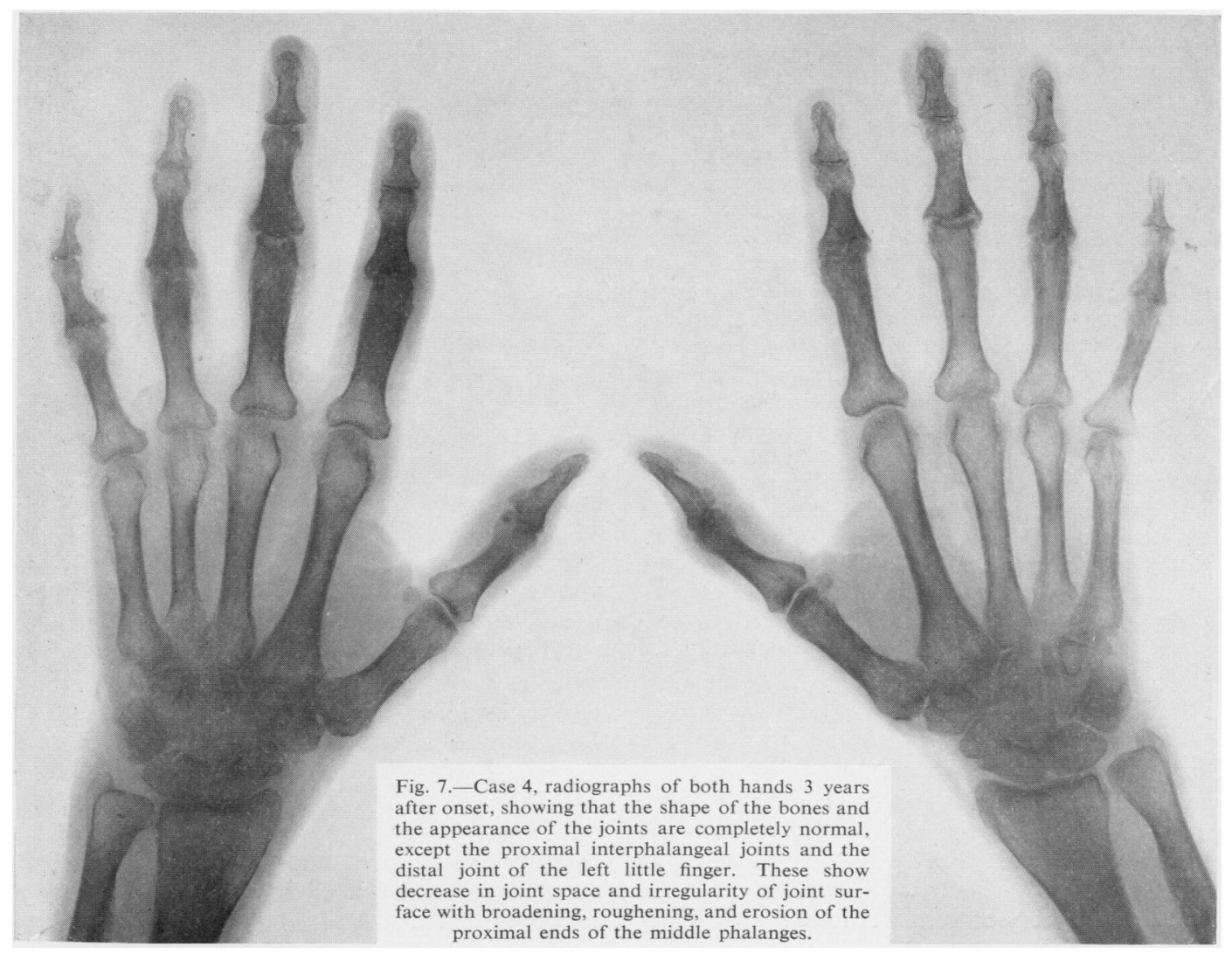


A similar process is suspected in the terminal joints of both little fingers and thumbs. The other joints of the hands and wrists are not affected. Lateral views of the fingers of the right hand taken in May, 1949 (Fig. 8), show irregularity of joint line and erosion of bone substance. There is bone production at the anterior and posterior profiles of the proximal ends of the middle phalanges.

Radiographs of both hands taken in July, 1955, 9 years after onset, showed a definite destructive process of the distal joints of the left thumb and left little finger but all of the proximal interphalangeal joints of the fingers were then completely ankylosed. Photographs at this time showed the skin of the fingers to be smooth and shiny with no remnants of the transverse creases normally present over the joints. The patient could not clench her fist because of the immobility of the proximal finger joints.

Lateral radiographs of all the fingers taken in July, 1955 (Fig. 9, opposite), show obliteration by bony ankylosis of all the proximal interphalangeal joints of the fingers, and the distal joints of the right little finger and the right thumb. No evidence of a joint space or joint line remains, the position of the joint being identified by smooth continuous fusiform enlargement of the bones. Spurs are now seen on the dorsal aspects of the proximal ends of the distal phalanges of all the fingers, except the right little finger, which are typical of those seen in Heberden's nodes.

The most recent radiographs taken in January, 1958, 12 years after the onset (Fig. 10, overleaf), show complete bony ankylosis of all of the proximal interphalangeal joints of both hands and the distal joint of the right little finger and thumb. The metacarpophalangeal joints are normal, except that of the left little finger which shows a cup-shaped deformity in the proximal end of the middle phalanx with erosion of the distal surface and irregularity of the proximal surface. Changes in the wrist show decrease in size of the proximal bones of the wrist, irregularity of joint surfaces between them and the radii and ulnae, and condensation of bone of the joint surfaces. The joint spaces are well preserved. The irregularities of mineralization are due to technical difficulties in making the photographic prints.

Thus, despite a destructive joint disease resulting in a complete bony ankylosis studied for 10 years, the diagnosis of rheumatoid arthritis is doubtful because of the sharp localization of the disease, the absence of constitutional symptoms, the only slightly elevated erythrocyte sedimentation rate, and the negative serological tests.

\section{Discussion}

Case histories, clinical records, and iconographic descriptions are given of four women, each of whom suffered from ankylosis of the interphalangeal joints of the fingers. The first two are cases of severe generalized rheumatoid arthritis. These patients had disease of long standing, with wide-

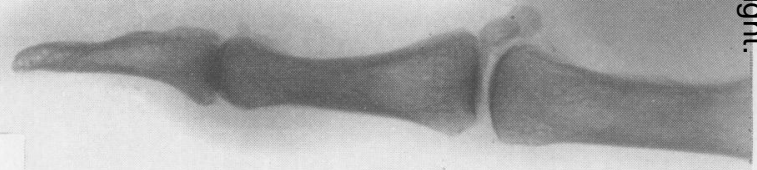

Fig. 8. - Case 4, lateral views of the fingers of the right hand 3 years after onset, showing most marked changes in the proximal joints. The joint spaces are irregular and the joint surfaces are roughened and broadened. Considerable bone destruction is visible. Spurs are seen on the distal phalanges.

spread joint damage throughout the body, and complete disablement. The patients were placed in Class IV, Stage IV, according to the classification adopted by the American Rheumatism Association. The other two cases differ from the first two in that permanent joint damage has been limited to the hands and constitutional symptoms, which were never severe, have completely disappeared. The patients seem to be in excellent health and only slightly handicapped by the changes in the hands. The third case has been classified as Class IV, Stage I, solely because some joints show complete ankylosis. Radiographic studies of the fingers show progression of the disease from a stage of fusiform enlargement and bone destruction about the proximal interphalangeal joints to the present condition when the bones are completely ankylosed 


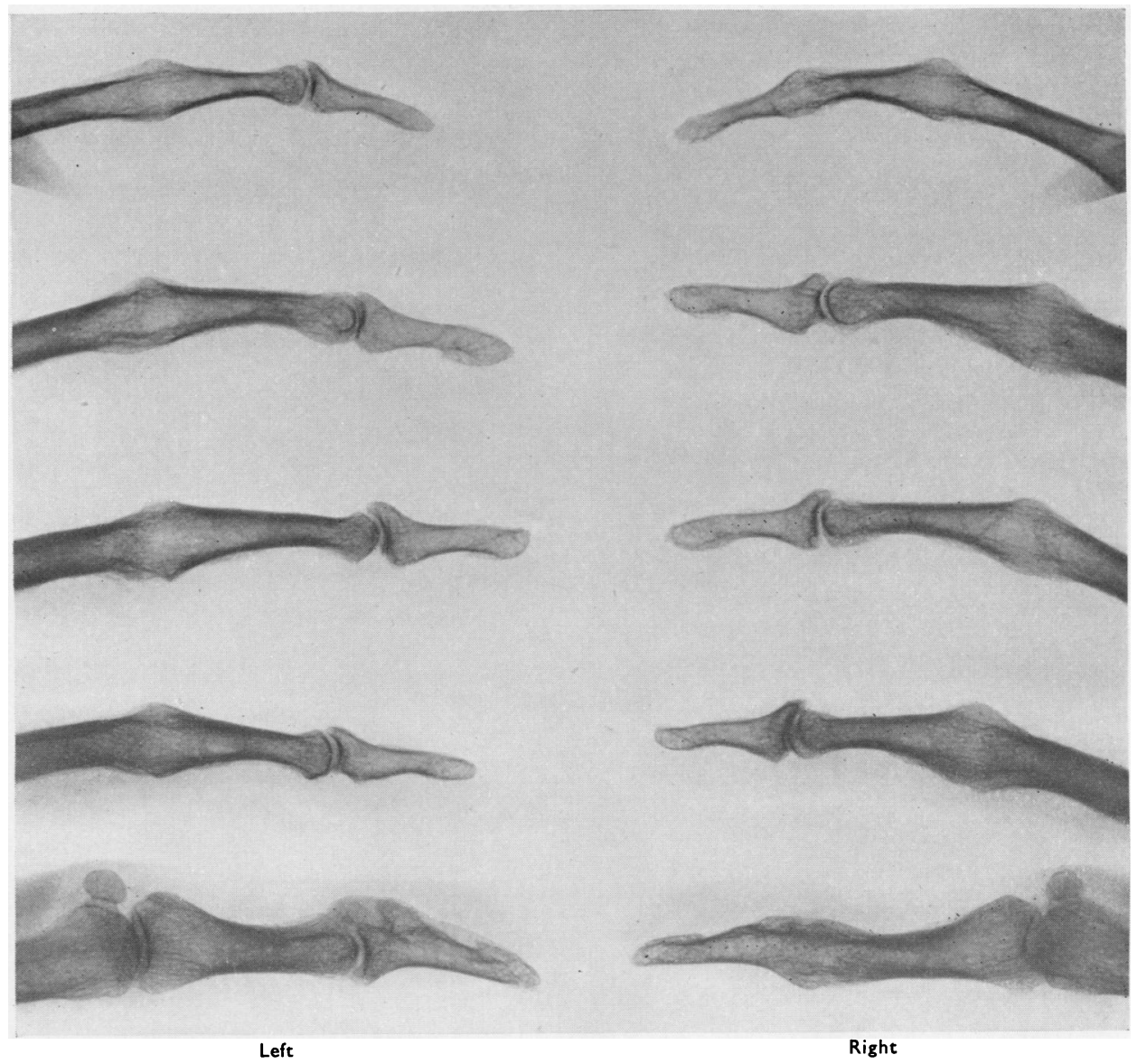

Fig. 9.-Case 4, lateral views of the fingers 7 years after onset, showing bony ankylosis of all the proximal joints and of the distal joints of the right little finger and thumb. Spurs are seen in the dorsal aspects of the proximal ends of the distal phalanges similar to those seen in Heberden's nodes.

and the fingers have regained their normal size. No other joint changes in the body are recognizable by clinical examination or by extensive radiographic survey. The diagnosis in this case is substantiated by positive serological tests on two occasions and an elevated erythrocyte sedimentation rate. A definite diagnosis is justified according to the proposed diagnostic criteria for rheumatoid arthritis, since there was at one time pain and tenderness, swelling, symmetrical involvement, radiographic changes, and a positive latex agglutination test. Despite the ankylosis, clinical activity is now minimal; the unusual aspects of the case are the very restricted distribution of joint involvement, the temporary and mild constitutional symptoms, and the complete restoration of health and activity for several years. If this patient were seen now and not carefully studied the diagnosis might easily be overlooked.
The fourth case is similar to the previous one in that the disease has been limited to the hands, and that constitutional symptoms have been mild and have now completely disappeared. In this patient the erythrocyte sedimentation rate has never exceeded $26 \mathrm{~mm} . \mathrm{Hg} / \mathrm{hr}$, and for the last 3 years has been below $10 \mathrm{~mm}$. The agglutination tests have been completely negative twice in the last year. A definite diagnosis is not so clearly justified according to the proposed diagnostic criteria. Symmetrical involvement, radiographic changes, and stiffness in symmetrical joints have been noted, but because she was not observed, during the early stages, details of her symptoms at that time are not known. The patient has been classified as Class IV because of bony ankylosis, but has been placed in the Stage I category because of her complete ability to carry on all her usual duties without handicap. She must be considered as at least a possible case 


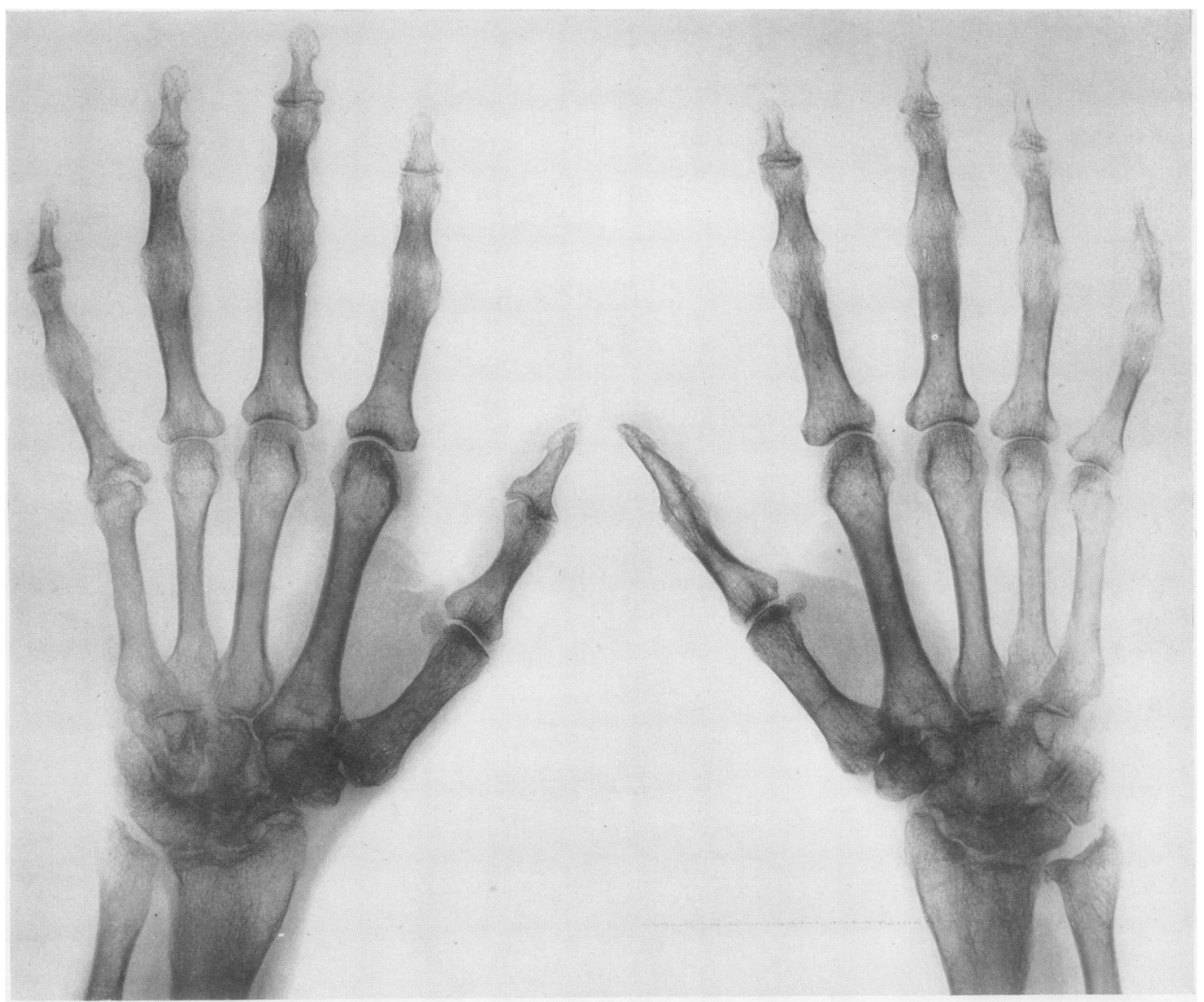

Fig. 10.-Case 4, radiograph 12 years after onset showing complete bony ankylosis of the proximal interphalangeal joints of both hands and of the distal joints of the right little finger and thumb. The metacarpophalangeal joint of the left little finger shows a cup-shaped deformity of the phalanx. Wrists show decrease in size of the proximal carpal bones.

of rheumatoid arthritis if not a probable case, but the diagnosis cannot be considered as proven.

Although discussion has been limited to a consideration of rheumatoid arthritis in these cases, there are certain additional features suggestive of degenerative joint disease. Lateral views of the fingers (Figs 5 and 9) show large spurs projecting dorsally from the proximal ends of the distal phalanges. These spurs are thick and have rounded ends suggestive of traumatic Heberden's nodes. It is unusual, however, to see six instances of traumatic Heberden's nodes in one individual as in Fig. 5. Idiopathic Heberden's nodes are usually associated with loss of joint space, greater irregularity of joint surface, and pointed spurs. Heberden's nodes with spurs as large as those shown here are always associated with considerable enlargement of the fingers, but these fingers were not enlarged in the region of the terminal joints. The carpal bones in Fig. 10 show changes in outline with loss of substance particularly of the semi-lunar bones. The joint spaces are adequately preserved and the joint surfaces are sharp and show condensation of bone. The rest of the carpal bones are not altered. These changes are difficult to classify because they seem to differ sharply from those usually seen in the arthritic diseases. Bone seems to have been absorbed, but there is no inflammation and the causative process seems to be completely quiescent and healed. Even if the changes in the terminal finger joints and the wrists are accepted as manifestations of osteo-arthritis, the limited distribution of these changes do not justify the characterization of the condition as generalized osteo-arthritis as described by Kellgren and Moore (1952).

\section{Summary}

Ankylosis of the phalanges without deformity is ? uncommon even in severe cases of rheumatoid 
arthritis. Four female patients who suffered from ankylosis of the interphalangeal joints of the fingers are described in detail.

Two had severe generalized rheumatoid arthritis leading to complete disablement, but in the other two permanent joint damage was limited to the hands and the mild systemic symptoms disappeared, leaving little if any disability.

\section{REFERENCES}

Kellgren, J. H., and Moore, R. (1952). Brit. med. J., 1, 181.

Ropes, M. W., Bennett, G. A., Cobb, S. Jacox, R. and Jessar, R. A (1957). Ann. rheum. Dis., 16, 118.

Stecher, R. M., and Hauser, H. (1948). Amer. J. Roentgenol., 59, 326.

(1954). Ibid., 72, 452.

Steinbrocker, O., Traeger, C. H., and Batterman, R. C. (1949) J. Amer. med. Ass., 140, 659.

\section{Ankylose des articulation digitales dans l'arthrite rhumatismale \\ RÉSUMÉ}

L'ankylose des phalanges sans déformation es peu commune même dans des cas sévères d'arthrite rhuma- tismale. On décrit en détail quatre cas de femmes atteintes d'ankylose des articulations interphalangiennes des doigts.

Deux d'entre elles souffraient d'une arthrite rhumatismale généralisée et sévère menant à l'incapacité totale, mais chez les deux autres le dommage se limitait aux mains, les symptômes généraux ayant disparu avec peu ou pas d'incapacité résiduelle.

\section{Anquilosis de las articulaciones digitales en la artritis reumatoide}

\section{SUMARIO}

La anquilosis de las falanges sin deformidad no es común hasta en los casos graves de artritis reumatoide. Se describen detalladamente cuatro casos de mujeres con anquilosis de las articulaciones interfalangeas de los dedos.

Dos de éstas sufrieron de una artritis reumatoide generalizada y grave conduciendo a la incapacidad total, pero en las demás el daño se limitó a las manos, los síntomas generales habiendo desaparecido con incapacidad residual poca o ninguna. 